\title{
Electronic Flight Bag in the Operation of Airline Companies: Application in Turkey
}

\author{
Savaş S Ateş \\ Faculty of Aeronautics and Astronautics, Anadolu University, Turkey
}

Copyright $₫ 2017$ by authors, all rights reserved. Authors agree that this article remains permanently open access under the terms of the Creative Commons Attribution License 4.0 International License

\begin{abstract}
Electronic Flight Bag (EFB) is a sophisticated technology which is aimed to be used in paperless flight operation in the airplane. Using of EFB is mainly planning to increase the efficiency of the aviation companies. In the scope of this research, the procedures of EFB usage in the flight operations and the advantages to airline companies are investigated. In the first part of the paper, the concept of efficiency is determined and requirements of flight operations planning procedures are investigated with literature review. In the second part, electronic flight bag is defined with the properties, types, services, and usage conditions. In the last part, the efficiency of EFB usage is estimated with the data which is collected by semi-structured interview method. The research was completed with 6 different participations from different airlines companies in Turkey. In the result of the paper, time-saving in data updating process is found to be one of the several advantages of EFB. Moreover, with the help of accelerated information process, companies may save more time with faster aircraft turnaround.
\end{abstract}

Keywords Electronic Flight Bag, Flight Operations, Information Technology

\section{Introduction}

Efficiency can be defined as the relationship between outcomes and the time spent achieving this result. As the time usage of operation to provide the desired result decreases, the efficiency of the system will increase at the same time. The increase in term of efficiency means better quality at the business level, lower costs, more production and more profit for all aviation-related companies. All cost-cutting measures and practices within the business/companies are directly or indirectly related to productivity. In general, all businesses aim to increase their profitability. For this reason, productivity can be regarded as the closest indicator of profit. For all these reasons, it would be quite appropriate to figure that productivity is one of the major functions of decisions made by businesses. Through information technology, knowledge has gained a common and universal character. The criteria for establishing a competitive advantage for the businesses of the information age in the same sector are related to the useful amount of information that they possess and their usage ratings. In this era, economies, societies, individuals, and institutions are globalizing and competition among all these factors is quite effective. Competition brings opposition of the phenomenon change. One of the most important factors in increasing the productivity of enterprises in today's environment is the utilization of technological developments [1].

Inputs are used in production and all processes of converting these inputs into output are expressed as production technology. Businesses are becoming increasingly productive by using disembodied and embodied technologies in production technologies. It refers to new technologies that are "embodied" in the monitoring of investment goods such as machinery and equipment, new capital goods and improvement in the quality and design of imported intermediate inputs. Learning by doing, and developments in the managerial organization mean "disembodied" technological developments [6],[7],[8]. Both embodied and disembodied technological developments increase the output level in short terms with efficiency gains.

Future EFB upgrades are expected to support real-time updates of time-sensitive data for example; in-flight weather reporting notices to airmen (NOTAM), and electronic checklist. Boeing Company is also cooperating with Jeppesen to use category 1 and 2 EFB systems on their airplanes, both for the ones which are on production and for active ones to improve. The first Class 3 EFB implementation is planned to be on the 777-200ER airplanes production line for KLM Royal Dutch Airlines [9].

The efficiency of airline operations; geography in which they operate, and the route structure of the main roads of that zone are difficult to compare because of the large external barriers that different airlines have, such as differences in the types of traffic experiences they have. Also; domestic 
problems such as trade union problems are left out of the direct control of the airline, it can place a significant burden on airlines to work towards maximum efficiency.

Updates to improve the efficiency of the airlines have a great effect on the following factors [10]:

1) Turnaround time

2) Aircraft utilization, Keeping Stage Length (Rate of Aircraft Usage)

3) Crew utilization

4) Control of Maintenance Time

5) Fuel Consumption

6) Payload on key flights

7) Fleet selection

8) Control of delay

9) Disruption management

Ground time covers the time spent at the airport from landing to departure. Turnaround time is the time frame designed to safely meet the operational needs of aircraft, passengers, cargo and crew within a period of time from aircraft landing to take-off. Turnaround time, which is an important indicator for the measurement of airport ground service operators' efficiency, should not be less than minimum ground time [2]. Average turnaround times are 1-2 hours for European and Asian origin airlines, 25-40 minutes for standard American airlines, and 45-75 minutes for wide-body aircraft. Southwest airlines are famous for their 10-15 minutes turnaround talent.

Aircraft utilization: The arrangement and operation of hubs in airline companies; There are important decisions that must be made regarding aircraft types and characteristics to ensure operational efficiency while airplane fleets are being configurated. Main elements when planning the fleet are; fleet age, aircraft size, aircraft engines and aircraft range.

Selected aircrafts during an aircraft fleet are being built; are selected by considering the tasks that airlines will perform according to their activities. Fleet requirements in commercial airlines are defined by taking numerous factors into consideration such as route structure, aircraft type rating, aircraft range, airport infrastructure restrictions. An airline should consider changing its fleet as soon as possible if it finds itself in a situation where the existing fleet is incompatible with the aims and operations of the airline [10].

The plan of the airline operation center varies from airport to airport. Some airline centers are basically organized through geographic coverage and some fleet types. All airline operations control centers have dispatchers, but organizational staff may change according to their duty-tree. Airline operation centers have their own meteorological departments. In particular, there is some staff assigned to the deterioration management and some are linked to the diversity of departments such as team planning, line maintenance, revenue management and advanced planning. For larger air carriers, operation control may include a central structure and station operation control sections. In general, dispatchers, aircraft programmers, or operation managers are responsible for making management decisions
[10].

The main purpose of this study is; to increase productivity by using electronic flight bag in the aviation business. To this end, the use of electronic flight bags in flight operations and the benefits that they provide to businesses have been examined and the relationship between the use of electronic flight bags and efficiency has been aimed to be examined.

\section{Definition of Electronic Flight Bag (EFB), Benefits and Services of EFB to Airlines}

At first, flight bag can be thought that it refers to any baggage taken on board of a flight, but usually, it refers to a specific type of document bag carried by pilots and flight crews. Items are commonly found in pilots' flight bags include:

1) Operating manuals for the aircraft being flown.

2) Operations manuals for the flight crew.

3) Aeronautical and navigational charts.

4) Jeppesen chart binders or "Jepps".

5) A Route Manual.

6) Flight checklists.

7) Logbooks.

8) Weather information.

Pilot's documentation and licenses(such as their passport, pilot's license, class-specific medical certificate), and equipment or accessories(such as a calculator, pens, sunglasses, radio headphones or binoculars). Electronic Flight Bag (EFB) is defined as a system that enables electronic documents to be reached and used in flight, which can be integrated with airborne avionics systems. Moreover, it also keeps the information on paper in electronic form for the flight crew.

EFB, in general, means a printed reference documents and it is also called "Flight Bag", which contains aircraft operating manuals, cabin operation manuals and navigation charts available to pilots before and during flight. Pilots can carry and use those documents on their flights by computer-based applications that will take their place. EFB also incorporate sub-applications in order to provide an automated calculation of pre-flight performance analysis.

The name of EFB is taken from a document bag weighing 20-25kg, which is carried by pilots for each flight. Electronic Flight Bag is an application that replaces these documents in the digital dimension. EFB applications are used on tablet computers ranging in weight from 0.5 to $2.2 \mathrm{~kg}$. Thus, the function of a traditional flight bag can be achieved with a tablet fixed to the aircraft or carried with the pilot. In the last few years, EFB systems have become more cost effective and have begun to take place in the civil aviation world, along with the cheaper mobile tablet hardware.

The usage of EFB has a number of advantages to airline companies. As the varieties of applications used and the content management and distribution systems in EFB 
changes, the specific benefits of EFBs are also changing and updating respectively. In general, benefits of using EFB are: The weight savings resulting positive effect on motions comparing to the substitution of the traditional use of the flight bag and the reduction in the health problems caused by the weight of the bag. Another one is a reduction in costs and the increased efficiency due to the elimination of the operations on the printed papers. Finally, a decrease in pilot workload creates situational awareness of pilots with automatic start and landing calculations resulting in a reduction of fuel and maintenance costs [5].

According to United Airlines, a conventional paper-based flight bag contains an average of 12,000 sheets of paper. The airline estimated that deployment of an EFB system running on Apple iPads would save the airline nearly 16 million sheets of paper a year, as well as save 326,000 gallons of jet fuel due to the reduced weight on board the aircraft.

\subsection{Classification and Specifications of EFB Systems}

Electronic flight bags can be examined in three classes according to the specifications of equipment; Class 1, Class 2 and Class 3 [3].

Class 1 EFB systems;

- are Commercial-Off-The-Shelf (COTS)-based computer systems commonly used for flight operations.

- $\quad$ are portable,

- are connected to the aircraft power with a certified power supply,

- are considered to Controlled Portable Electronic Devices (PED),

- are not connected to the mounting device in the aircraft,

- have not aircraft data connection except for certain conditions,

- do not require the approval of airworthiness [4].

Class 2 EFB systems;

- are Commercial-Off-The-Shelf (COTS)-based computer systems commonly used for flight operations.

- $\quad$ are portable,

- $\quad$ are connected to the aircraft power with a certified power supply,

- $\quad$ are considered to be Controlled Portable Electronic Devices (PED),

- are connected to the mounting device in the aircraft,

- can be connected to avionic systems,

- require the approval of airworthiness [4].

Class 3 EFB systems are installed as equipment that requires airworthiness approval. This approval (including EFB hardware installation integrity, e.g. server, screen, keyboard, power, maneuver) includes aspects of human and machine interface compatibility including hardware and software qualities [4].

Type A software applications are available in the form of pre-existing data in a paper format [11]. They can be included in any hardware class, require operational approval, and do not require the approval of airworthiness.

Type B software applications include dynamic and interactive applications that you can modify in data and presentations [11]. They can be included in any hardware class that does not require the approval of airworthiness.

\subsection{Operational Evaluation and Approval Process of EFB}

Efficiency can be defined as the relationship between outcomes and the time spent to achieve this result. As the time spent to the desired result decreases, the efficiency of the system increases. Efficiency increase means better quality at the business level, lower costs, more production and more profit. All cost-cutting measures and practices within the business/companies are directly or indirectly related to productivity. In general, all businesses aim to increase their profitability. For this reason, productivity can be regarded as the closest indicator of profit. For all these reasons, it would be appropriate to think that productivity as a function of some decisions made by businesses. Through information technology, knowledge has gained a common and universal character. The criteria for establishing a competitive advantage for the businesses of the information age in the same sector are related to the useful information they possess and their usage ratings. In this era, economies, societies, individuals, and institutions are globalizing and competition among all these factors is essential. Competition brings the opposition of change phenomenon with it. One of the most important factors in increasing the productivity of enterprises in today's conditions is the utilization of technological developments [1].

The main purpose of this study is; to increase productivity by using electronic flight bag in the aviation business. So that, usage of electronic flight bags in flight operations and the benefits that they provide to businesses have been examined and the relationship between the use of electronic flight bags and efficiency has been tried to be examined.

Parts which are needed to be added to airplanes pass through various processes. At the end of these processes, they can be added to aircraft if they are approved. According to JAA, some points should be considered in the evaluation of approval process of EFB as follows [4]:

- Risk assessment

- $\quad$ Role of System Supplier

- Human-Machine Interface Application Evaluation / Human Factors

- $\quad$ Flight Crew Working Procedures

- Quality assurance

- Compliance Monitoring

- Role of EFB Manager

- Flight Crew Training

- System Security

- Operational Evaluation Test

- Operational Compliance Summary 


\section{Materials and Methods}

In this research, in order to observe the increase of efficiency by using electronic flight bag; concept, relation, and the importance of efficiency to technological developments have been overviewed. Elements necessary for aviation companies to use electronic flight bags in flight operations, and usage of electronic flight bags in flight operations have been examined.

The research consists of three parts. In the first part, the concept of productivity and the factors that are considered in the planning of flight operations are examined in detail. In the second part, electronic flight bags were introduced. EFB characteristics and service conditions that are required to be used in flight operations have been expressed. In the third part, operational efficiency effect of electronic flight bags has been examined in detail according to the information obtained from the interviewees who operate electronic flight bags.

Aviation companies have started to use electronic flight bags since the mid-1990s in the cockpits. Limited time, limited interviews with aviation company personnel and a limited number of electronic flight documents are some of the limiting factors. Various questions have been tried to be answered. The questions asked in this interview are as follows:

1. What are the things to be done in order to improve the efficiency of documentation in aviation operations?

2. What are the contributions of the EFB application to flight performance?

3. What are the operational conveniences provided by the EFB application?

4. What is the share of EFB implementation in increasing the efficiency of the airline company?

5. What are the contributions of the EFB application for a profitable and sustainable flight?

6. What are the benefits of current and fast information access to operational efficiency and effectiveness?

7. What are the benefits of EFB in improving flight efficiency and flight/pilot performance?

In this study, face to face interviews have been conducted with the aviation company personnel within the scope of the interview form prepared before the interview.

\section{Results and Discussion}

\subsection{Demographic Data}

The professions of aviation companies' personnel are as follows:

- $\quad$ Performance Specialist

- Captain Pilot/ Safety Manager

- Safety Manager

- EFB coordinator

- Captain Pilot

- $\quad$ Flight Operations Center Director

The answers given to the "What is your field of expertise?" question are as follows:

- $\quad$ B737 Pilot

- $\quad$ EFB Admin

- Industrial Engineering

- $\quad$ Pilotage / Flight Safety

- Quality

- $\quad$ Flight Performance

The table below shows the information about the "How do you define your position in the business/company?” question according to the answers given in the interviews.

Table 1. Participants' positions in their organizations

\begin{tabular}{|c|c|c|}
\hline Senior manager & 1 & $17 \%$ \\
\hline Mid-level manager & 3 & $50 \%$ \\
\hline Sub-level manager & 0 & $0 \%$ \\
\hline Other & 2 & $33 \%$ \\
\hline
\end{tabular}

\subsection{Relationship between EFB Systems and Businesses' Operations}

The table below shows the information obtained in relation to the EFB systems and the businesses' operations according to the answers given in the interviews.

Table 2. Factors Affecting Business Productivity

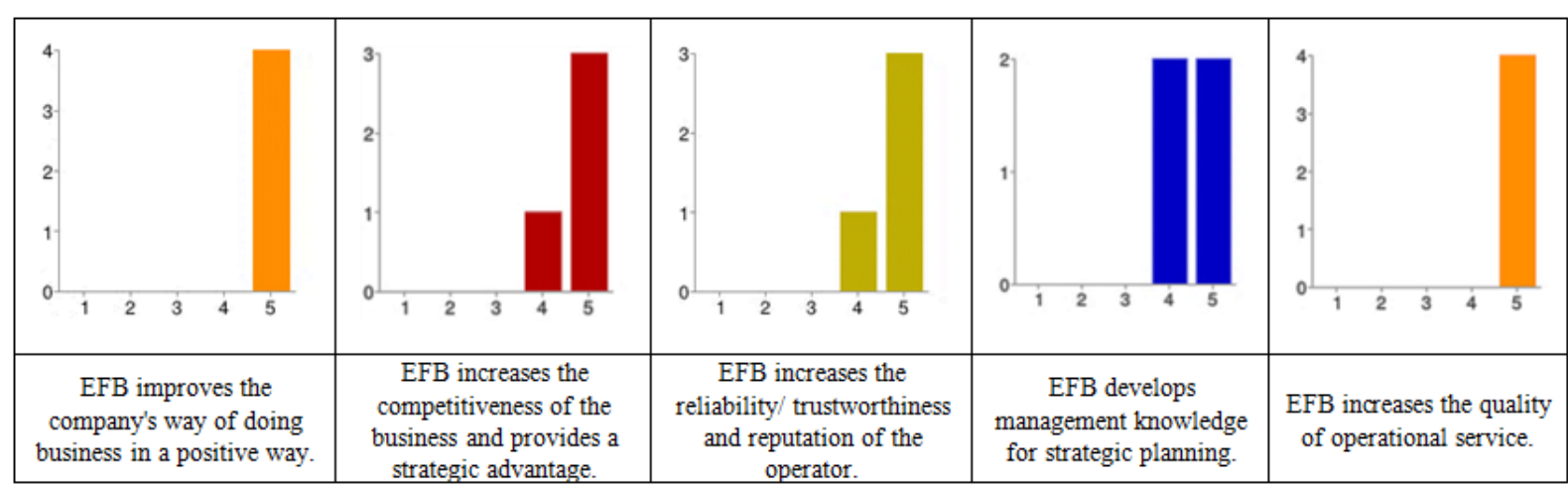




\subsection{Relationship between EFB Systems and Operational Information Flow}

With the usage of EFB systems, operators can access information about flight operations more quickly and easily. In EFB systems, the information required by users is presented in a much better format in an electronic environment. Information is stored in the electronic environment by minimizing the error rate caused by human factors and enhancing the reliability and authenticity of the information presented to the user. The use of EFBs in flight operations provides more accurate information for operational control of the user. By using EFB, it is possible to provide more information to relevant users for administrative control purposes when necessary. The table below shows the information obtained in relation to EFB systems and operational information flow according to the answers given in the interviews.

Table 3. The answers about relationship between EFB systems and operational information flow

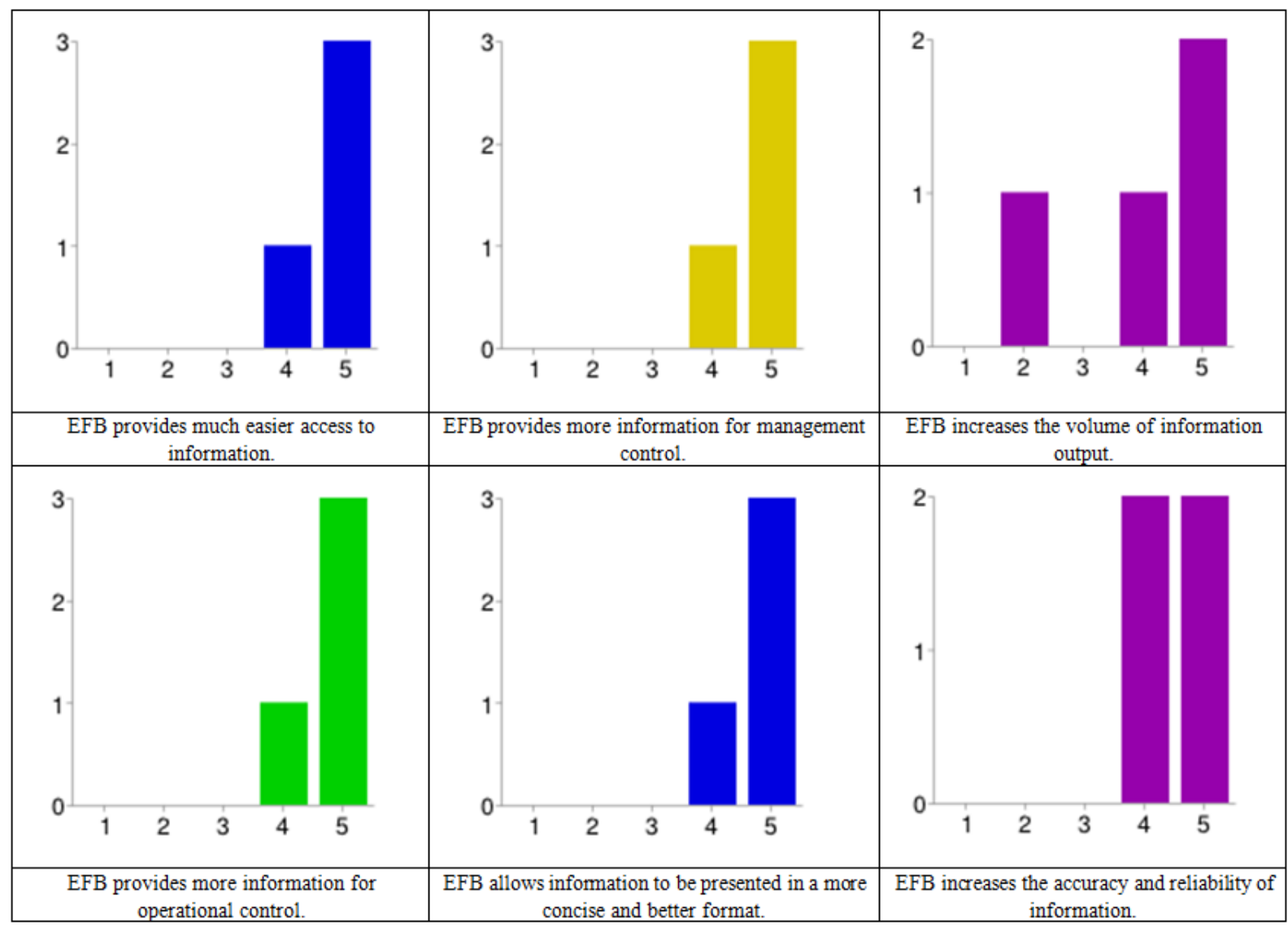

\subsection{Relationship between EFB Systems and Organizational Structure}

The table below shows the information obtained in relation to the EFB systems and the organizational structure according to the answers given in the interviews. 
Table 4. The answers about relationship between EFB systems and organizational structure

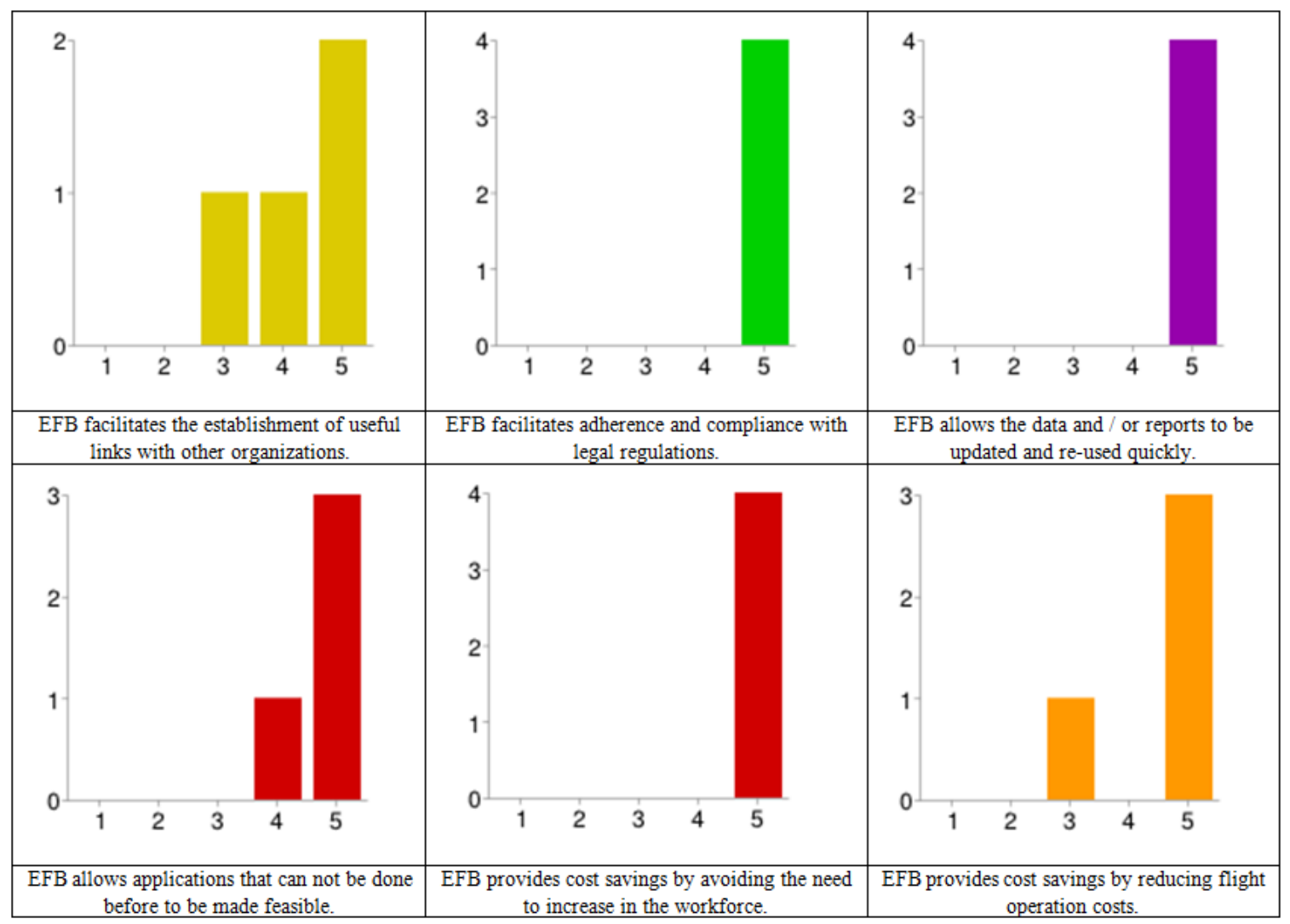

\subsection{Relationship between the Usage of EFB Systems and Cost Saving}

Businesses saving data updating process with the services and facilities/convenience provided by EFB systems, reaches faster turnaround structure. Having the ability to make more flights by saving operational time allows airline operators to run and handle more flights with the same resources. This provides long-term cost savings to businesses.

Table 5. Relationship between the use of EFB systems and cost saving

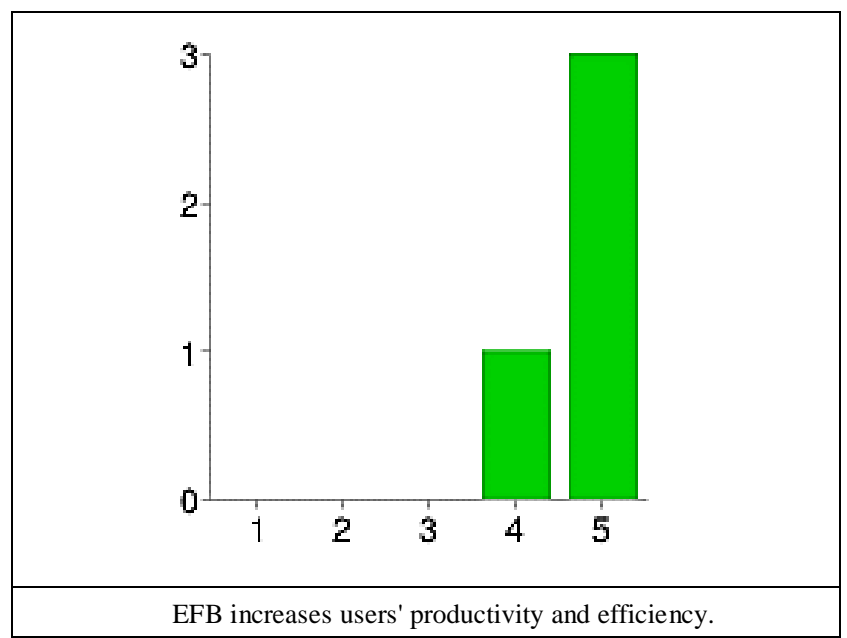

\section{Conclusions}

In a business, efficiency refers to a measure of how effectively resources are used. Today, technology is developing rapidly and many technological innovations are joining our life together with developing the technology. When businesses use their resources effectively, they gain competitive advantages against their competitors in the same field. Their abilities to survive in this challenging competitive environment are closely connected with having technological innovations and using their resources effectively. Therefore, with the developing technology, businesses intend to integrate their technological developments into their activities. Therefore they aim to increase their efficiency by using their resources more correctly and effectively.

The aviation sector is a sector where high technology is used and competition is intense. The success of aviation businesses in the sectoral context is strongly related to the efficiency of flight operations. One of the recent technological advances used by aviation companies is electronic flight bag. Electronic Flight Bag (EFB) is a system that enables electronic documents to be transferred and managed in flight. It can be integrated with avionic systems and keeps the information in electronic form that pilots needed.

In this study, the effect of using electronic flight bags in 
flight operations has been examined. After analyzing the results of research, it is observed that businesses resources can be used more efficiently with the assistance of electronic flight bags. It has been revealed that EFB system provides many advantages to the operators.

Generalizability of the results is not appropriate with the number of participants. However, there are major consequences in the direction of study findings in the research. The use of electronic flight bags enables businesses to store, update and transfer the necessary information through the electronic environment, and transfer processes between related departments and electronic flight bag users provide a high time utility. It enables flight operation processes to be carried out rapidly and information flow in an electronic environment is up-to-date and quite fast. Thus, EFB system enables businesses to use their time much more effectively and efficiently. Usage of electronic flight bags makes the flight operation processes in the cockpit more time efficient and accurate with the facilities and services. All of these services and facilities provided by electronic flight bags result in long-term cost savings to carriers in the aviation sector where punctuality is crucial. In general, if EFB services, facilities, and utilities are evaluated, it is clearly shown that usage of EFB greatly increases the productivity of enterprises.

In the future, with the developing technology, it can be foreseen to add voice command feature and three-dimensional chart display services to electronic flight bags, in order to enable live connection with air traffic units. EFB combinations with other technologies such as Google Glass instead of tablets are among the alternative technologies related to the usage of this application.

\section{REFERENCES}

[1] Güngör, M. (2012). İSTİHDAM VE VERIMMLİLIK İLISSTISİ: ISSO'DA FAALIYET GÖSTEREN 500 BÜYÜK FIRMA ÜZERINE BIR UYGULAMA. Gaziantep.

[2] IATA. (2011). Airport handling manual. Geneva: IATA Publication.

[3] ICAO. (2014). Annex II - AMC 20-25. ICAO

[4] JAA Administrative \& Guidance Material. (2014). Operations, Part Three: Temporary Guidance Leaflets (JAR-OPS)/ LEAFLET No. 36: APPROVAL OF ELECTRONIC FLIGHT BAGS (EFBs).

[5] Köse, M., Ayanoğlu, E., Erel, E., \& Gündüz, C. (no date). Sivil Havacılıkta Mobil Teknolojilerin Kullanımı -Elektronik Uçuş Çantasi.

[6] OECD. (2001). Measuring Productivity- Measurement of Aggregate and Industry Level Productivity Growth, Paris.

[7] Suiçmez, H. (2008). Ekonomik Büyümede Toplam Faktör Verimliliğinin Rolü. Ankara: Milli Prodüktivite Merkezi Yayınları.

[8] Suiçmez, H. (2009: a). Verimlilik ve İstihdam. Ankara: Milli Prodüktivite Yayınları.

[9] Allen, D. (2003, 06 25). Electronic Flight Bag. Retrieved from boing commertial:

http://www.boeing.com/commercial/aeromagazine/aero_23/ EFB.pdf

[10] Keller, M., \& Butler, G. (2000). Handbook of Airline Operations. Aviation Week.

[11] JAA Administrative \& Guidance Material. (2014). Operations, Part Three: Temporary Guidance Leaflets (JAR-OPS)/ Leaflet No. 36: Approval of Electronic Flight Bags (EFBs). 